\title{
Enhancing the relevance of Shared Socioeconomic Pathways for climate change impacts, adaptation and vulnerability research
}

\author{
Bas J. van Ruijven • Marc A. Levy • Arun Agrawal • \\ Frank Biermann • Joern Birkmann • \\ Timothy R. Carter $\cdot$ Kristie L. Ebi • \\ Matthias Garschagen • Bryan Jones • Roger Jones • \\ Eric Kemp-Benedict • Marcel Kok • Kasper Kok • \\ Maria Carmen Lemos • Paul L. Lucas • Ben Orlove • \\ Shonali Pachauri • Tom M. Parris • \\ Anand Patwardhan - Arthur Petersen • \\ Benjamin L. Preston • Jesse Ribot • Dale S. Rothman • \\ Vanessa J. Schweizer
}

Received: 18 January 2013 / Accepted: 26 August 2013 / Published online: 18 September 2013

(C) The Author(s) 2013. This article is published with open access at Springerlink.com

\begin{abstract}
This paper discusses the role and relevance of the shared socioeconomic pathways (SSPs) and the new scenarios that combine SSPs with representative concentration pathways (RCPs) for climate change impacts, adaptation, and vulnerability (IAV) research. It first
\end{abstract}

\footnotetext{
This article is part of the Special Issue on "A Framework for the Development of New Socio-economic Scenarios for Climate Change Research" edited by Nebojsa Nakicenovic, Robert Lempert, and Anthony Janetos.
}

Electronic supplementary material The online version of this article (doi:10.1007/s10584-013-0931-0) contains supplementary material, which is available to authorized users.

B. J. van Ruijven $(\bowtie) \cdot$ B. Jones $\cdot$ V. J. Schweizer

NCAR, PO Box 3000, Boulder, CO 80307, USA

e-mail: vruijven@ucar.edu

M. A. Levy

CIESIN, Palisades, NY, USA

A. Agrawal • M. C. Lemos

University of Michigan, Ann Arbor, MI, USA

F. Biermann $\cdot$ A. Petersen

IVM, VU University, Amsterdam, Netherlands

J. Birkmann · M. Garschagen

UNU-EHS, Bonn, Germany

T. R. Carter

SYKE, Helsinki, Finland 
provides an overview of uses of social-environmental scenarios in IAV studies and identifies the main shortcomings of earlier such scenarios. Second, the paper elaborates on two aspects of the SSPs and new scenarios that would improve their usefulness for IAV studies compared to earlier scenario sets: (i) enhancing their applicability while retaining coherence across spatial scales, and (ii) adding indicators of importance for projecting vulnerability. The paper therefore presents an agenda for future research, recommending that SSPs incorporate not only the standard variables of population and gross domestic product, but also indicators such as income distribution, spatial population, human health and governance.

\section{Introduction}

Over the past three decades, scenario analyses have occupied a central role in assessments of the potential impacts of climate change on natural and human systems at different scales during the $21^{\text {st }}$ century. Whereas early studies used scenarios to explore the impacts of climate change on the physical system alone, from the late-1990s onwards there was an increasing recognition of the need to integrate the human dimensions of global change into impact studies. Social, economic, and technological changes and vulnerabilities will be fundamental determinants of future natural and human system risks and responses under a changing climate (Carter et al. 2001, 2007). Recently, the number of sub-global scenario studies of climate impacts, adaptation, and vulnerability (IAV) has increased. These studies

K. L. Ebi

ClimAdapt LLC, Los Altos, CA, USA

R. Jones

Victoria University, Melbourne, Australia

E. Kemp-Benedict

SEI, Bangkok, Thailand

M. Kok $\cdot$ P. L. Lucas $\cdot$ A. Petersen

PBL Netherlands Environmental Assessment Agency, Bilthoven, Netherlands

K. Kok

Wageningen University, Wageningen, Netherlands

B. Orlove

Columbia University, New York, NY, USA

S. Pachauri

IIASA, Laxenburg, Austria

T. M. Parris

ISciences, L.L.C., Burlington, VT, USA

A. Patwardhan

University of Maryland, College Park, MD, USA

B. L. Preston

ORNL, Oak Ridge, TN, USA

J. Ribot

University of Illinois, Urbana, IL, USA

D. S. Rothman

University of Denver, Denver, CO, USA 
increasingly adopt socioeconomic scenarios for specific regions, countries, cities, and sectors (Kok et al. 2011; Preston et al. 2011). Some limitations of these studies include:

- Use of sub-global future socioeconomic scenarios with context-specific, bottom-up processes that may be disconnected from global scale processes, limiting opportunities for comparison across studies and reducing the usefulness of the results for decision makers (Hallegatte et al. 2011; Kriegler et al. 2012; Ribot 1995).

- Time scales of regional and local socioeconomic scenarios tend to be shorter than those of many climate change scenarios: there is a reluctance to project trends in socioeconomic conditions out beyond a few decades, whereas climate scenarios extend through the end of the 21st century. Although there are qualitative descriptions of how variables describing adaptive capacity ${ }^{1}$ could change over time, these are rarely quantified. Instead, it has been common to represent these using recent socioeconomic indicators found from official statistics or survey data. Often, these are used in conjunction with future scenarios of climate hazards (e.g. changes in maximum temperature extremes by $2050)$ to characterize future vulnerability. ${ }^{2}$

- Methods to develop scenarios are sometimes ad-hoc and diverse (Preston et al. 2011).

A recent initiative to develop a new set of global socioeconomic scenarios to serve different areas of climate change research using a matrix architecture including Shared Socioeconomic Pathways (SSPs) and Representative Concentration Pathways (RCPs) (Ebi et al. this issue; Kriegler et al. this issue; O'Neill et al. this issue; van Vuuren et al. 2011, this issue) may offer new opportunities to increase coherence between scenarios at different scales and expand their use in IAV studies. This broadening analytical frame should, in turn, provide fresh insights into how future socioeconomic conditions may determine the magnitude and extent of potential climate change risks as well as society's ability to adapt. RCPs characterize varying levels of greenhouse gas and aerosol concentrations in the atmosphere as well as changes in land use that can affect the global climate during the 21 st century and beyond (van Vuuren et al. 2011) and are being used as inputs to climate models in the Climate Model Intercomparison Project (CMIP5-Taylor et al. 2011).

A framework for constructing scenarios using SSPs and RCPs is described in this issue (Kriegler et al. this issue; O'Neill et al. this issue; van Vuuren et al. this issue) and narrative descriptions of five SSPs have been drafted (O’Neill et al. forthcoming). Quantification of several SSP elements is underway using Integrated Assessment Models (IAMs). Some of the key drivers of social, economic, and environmental change, such as population and gross domestic product (GDP) are globally specified on the country-level. The development of SSPs is proceeding in two stages, with a "basic" set of SSPs being developed that include broad-scale narratives and global quantifications. This high-level set of global SSPs establishes a platform for developing "extended" SSPs that include substantive elaborations for specific sectors and regions. The matrix architecture of combining SSPs with RCPs into new scenarios allows IAV researchers to ask questions such as: "what could be the impacts of a given amount of climate change in worlds characterized by different development pathways?" (i.e. combining a single RCP with multiple SSPs), or "what could be the impacts of different levels of climate change under one possible future world?" (i.e. combining a single

\footnotetext{
${ }^{1}$ We here use adaptive capacity to refer to the combination of all the strengths, attributes, and resources available to an individual, community, society, or organization that can be used to adapt to a changing climate change (IPCC 2012).

${ }^{2}$ Vulnerability is a contested term in the literature (Hinkel 2011; Preston et al. 2011; Rothman et al. this issue). We here use the definition of the IPCC SREX, which defines vulnerability generically as the propensity or predisposition to be adversely affected (IPCC 2012).
} 
SSP with multiple RCPs). The unpacking of the scenarios into climate, development pathway, and policy provides researchers with a tool kit for asking more policy relevant questions than were possible with earlier scenario sets.

The process of new scenario development offers new opportunities for advancing the use of scenarios in IAV studies (see e.g. Rothman et al. this issue; Wilbanks and Ebi this issue). The process could be enhanced by addressing the question of how to bridge the scales between the global and the regional, local, and sectoral interests of the IAV community. The literature provides numerous and diverse examples of approaches for bridging across scales, but such methods can introduce further uncertainties and raise questions of internal consistency. Also, earlier global scenario sets lack a number of elements of socioeconomic development relevant to IAV analyses including trajectories of key indicators to characterize vulnerability and adaptive capacity.

In this paper, we explore how the SSPs and new scenarios can be made more useful to IAV researchers. What methods exist to extend the SSPs across multiple scales, and how can the SSPs increase coherence among studies with a strong bottom-up component? What elements and variables have IAV researchers added to global scenarios in the past, in order to be able to use them in IAV analyses? We aim to find a pragmatic compromise between generating as many indicators and variables as possible, whilst also recognising that only a limited number of variables can be meaningfully projected.

Section 2 discusses the main uses of socioeconomic scenarios in IAV analyses and details the elements and indicators needed for such studies. Section 3 presents an overview of the use of global environmental scenarios during the past decade for IAV studies and identifies shortcomings of those scenarios for IAV applications. Section 4 discusses methods for working across scales, and presents a rationale and procedures for adding additional elements to the SSPs. Finally, Section 5 surveys some of the remaining challenges and offers concluding remarks.

\section{The use of socioeconomic scenarios in IAV analyses}

Socioeconomic scenarios have varied uses in impacts, adaptation, or vulnerability studies, each application placing different demands on the types of scenario information required (Carter et al. 2001, 2007). Impact studies analyze the impacts and risks of climate changes for human and natural systems, with the aim to estimate the character, magnitude and rate of impacts across a number of contrasting scenarios and to investigate the effectiveness of various mitigation or adaptation measures in reducing risks or exploiting opportunities. In these studies, socioeconomic development pathways are generally used to characterise future exposure to climate changes. Studies focusing on adaptation require scenarios that characterise the conditions, incentives or barriers that affect adaptation options and adaptive capacity. Here, different socioeconomic scenarios can be combined with different climate scenarios to estimate the effectiveness of adaptation, residual damages after mitigation and adaptation, and the associated costs. In research on vulnerability, scenarios can be used to enhance understanding of the key factors predisposing systems and communities to potential adverse impacts of climate change, exploring how causal relations between those factors might develop or change in the future. Key questions for vulnerability and adaptation studies include "adaptation to what?", "who or what adapts?", "how does adaptation occur?", "have objectives been achieved?" (Funfgeld and McEvoy 2011; Preston and Stafford-Smith 2009; Smith et al. 2000). Each of these questions is dependent upon socioeconomic futures. More discussion on the role of vulnerability assessment and an explicit discussion of the (lack of) use of socioeconomic scenarios in IAV research and the potential consequences of that can be found in Preston et al. (2011). 
The applications of scenarios for IAV studies pose high demands on socioeconomic scenarios in terms of delivering specific information at the scale of analysis and for the number of variables required to describe future vulnerability and adaptive capacity. The selection of appropriate variables to describe the different dimensions of vulnerability and adaptive capacity is still under discussion. Factors describing vulnerability are often highly context specific, and one formidable challenge is to translate these into general variables that can be flexibly applied across different contexts. Further difficulty is introduced in attempting to quantify factors that are inherently qualitative, such as the quality of governance or levels of participation in decision-making. Several new vulnerability indices have recently been developed, such as the indicators for susceptibility, coping capacity and adaptive capacity in the World Risk Index (WRI) (Birkmann et al. 2011) and the Global Adaptation Index (GAIN: Global Adaptation Institute 2011) (see Table 1). In this regard it is important to note that some of these risk, vulnerability and adaptation index approaches use various indicators that are also applied in the SSPs and global impact models, hence it would be possible to explore more intensively the usefulness of scenarios in these vulnerability and risk assessments (see Birkmann et al. 2013). Nevertheless, the above challenges remain relevant and the utility and legitimacy of such indices is still contentious (Barnett et al. 2008; Hinkel 2011).

\section{Global scenarios of the past decade and their use and shortcomings for IAV analyses}

Over the past decade, several global scenario sets for global environmental assessments were developed (van Vuuren et al. 2012a) such as the IPCC SRES (Nakicenovic et al. 2000), the Global Environmental Outlook scenarios (GEO) (UNEP 2002, 2007) and the Millennium Ecosystem Assessment (Carpenter et al. 2005). The Special Report on Emissions Scenarios (SRES) presented scenarios of greenhouse gas emissions for mitigation research, consisting of simple storylines and model quantifications. The four global and seven regional GEO scenarios have a broader scope, characterising drivers of global environmental change and explicitly including indicators related to poverty, educational attainment, and malnutrition, as well as discussing progress on achieving the Millennium Development Goals (MDGs). The design of the Millennium Ecosystem Assessment (MA) scenarios was similar to that of SRES, but with a focus on ecosystems and human well-being rather than on climate change. An innovative aspect of the MA-scenarios was the multi-scale design. Besides global scenarios, much effort was directed to 35 sub-global assessments linking across scales. This resulted in a large body of empirical evidence and methodological findings of how to develop multi-scale scenarios (Zurek and Henrichs 2007). The results of the MA spurred thinking on the role of global scenarios in sub-global studies.

In practice, these global scenarios - at least in their original form - had limited application to IAV analyses (Arnell et al. 2004; Kriegler et al. 2012) because the storylines, assumptions, and model outputs were elaborated at different scales than those needed for most IAV studies. The GEO and MA scenario exercises were partly designed to overcome this limitation by nesting global and regional scenarios. However, as these exercises did not use climate model runs, there are only a few applications in IAV studies (e.g. Kok et al. 2011). For the SRES, climate runs based on emissions and land use are available, but offer only limited elaboration of socioeconomic variables and regional information. However, the storylines offer a guide for additional assumptions for climate impact and mitigation analyses (Nakicenovic et al. 2000); examples include institutions and governance (Berkhout et al. 2002), land use (Rounsevell et al. 2006), income distribution and poverty (Calzadilla 2010), and regional exercises (Carter et al. 2004; Holman et al. 2005). However, although many IAV studies use SRES-based climate 
Table 1 Overview of variables and indicators available from several global scenario sets (A), those added to the SRES scenarios in individual IAV studies for different sectors (B), and those included in two vulnerability indices $(\mathrm{C})$

\section{A: Scenario set \\ SRES (Nakicenovic et al. 2000) \\ GEO (UNEP \\ 2002, 2007) \\ MA (Carpenter \\ et al. 2005) \\ B: Impact sector \\ Water (Döll 2009; \\ Hinkel et al. 2012; \\ Nicholls 2004; Pérez \\ Urrestarazu et al. 2010) \\ Agriculture (Parry et al. 2004; Verburg et al. 2008; Wu et al. 2011) \\ Ecosystems (Golding and Betts 2008; Metzger et al. 2008) \\ Health (McCarthy et al. 2010; van Lieshout et al. 2004) \\ C: Vulnerability Index \\ World Risk Index \\ (Birkmann et al. 2011)}

GAIN index (Global

Adaptation Institute (2011))

\section{IAV-relevant variables}

Population, GDP

Added later: downscaled spatial population, downscaled spatial/ national GDP, institutions and governance, land use, income distribution and poverty, regional scenarios

Population, GDP, Trade, Gini index, population in extreme poverty, malnourished children, primary education enrolment, education gender ratio, life expectancy, land use, forest land, erosion risk, yield, food availability, water withdrawal, population under water stress, untreated wastewater, biodiversity, fisheries,

Quantitative: Population, GDP, Land use, Fertilizer use, Crop yield, Biodiversity, Water availability

Qualitative description of: Material needs, Health, Security, Social relations and Freedom of choice and action, Ecosystem services

Additional variables/indicators added

Spatial population, spatial/national GDP, Human Development Index

Spatial population, spatial/national GDP, food demand, trade, yield

Spatial population, spatial/national GDP, technology, deforestation

Spatial population, spatial/national GDP, adaptive capacity, groups under risk

Socioeconomic indicators

Public infrastructure: population without sanitation, without water access

Nutrition: share of population undernourished

Poverty and dependency: dependency ratio, population in extreme poverty

Economic capacity and distribution: GDP, Gini index

Government: Corruption Index, Good governance

Medical services: nr. of physicians, nr. of hospital beds

Material coverage: insurances

Education and research: adult literacy rate, gross school enrolment

Gender equity: gender parity in education, female reps. in national parliament

Environment/Ecosystem protection: management of water, forest and agriculture

Investment: public health expenditure, life expectancy at birth

Freshwater extraction, Mortality under 5, rural population, food import share, $\mathrm{nr}$ of health workers, health expenditure, urban population in slums, excess urban growth, threatened species, population $<5 \mathrm{~m}$ above sea level, energy at risk, paved roads, business freedom, trade freedom, fiscal freedom, government spending, monetary freedom, investment freedom, financial freedom, voice and accountability, political stability and violence, corruption, mobile phones, labor freedom, education enrolment, rule of law 
projections, only a few studies use socioeconomic projections, mostly limited to downscaled projections of population and GDP (Carter et al. 2007). The first set of these downscaled SRES projections was published by Gaffin et al. (2004) using simple techniques. More refined methods of downscaling were published later. One of these accounts for partial convergence in per capita GDP within world regions based on the SRES storylines (van Vuuren et al. 2007). Another distinguishes urban and rural areas in population and GDP projections and adds a geographic gravity model framework (see Section 4.2.2) to represent urban spatial expansion more effectively (Grübler et al. 2007).

IAV studies that used these downscaled projections for population and GDP also sometimes included additional elements; examples include studies of water availability and flooding that used assumptions about development indicators and sectoral scenarios (Döll 2009; Hinkel et al. 2012; Nicholls 2004; Pérez Urrestarazu et al. 2010). Studies of agricultural impacts made additional assumptions about food demand, trade, yields, and other sectoral information (Parry et al. 2004; Verburg et al. 2008; Wu et al. 2011). Ecosystem impact studies made additional assumptions about technology and deforestation (Golding and Betts 2008; Metzger et al. 2008). Population and health studies have used downscaled population (McCarthy et al. 2010) combined with expert judgment on adaptive capacity instead of using the socioeconomic assumptions in the SRES (van Lieshout et al. 2004). Overall, studies that use the SRES tend to focus more on impacts than on vulnerability or adaptive capacity, possibly because of the paucity of relevant variables.

Some reasons why the SRES, MA, and GEO scenarios have been of limited use to IAV researchers include:

- Climate projections were not available to match the socioeconomic scenario elements for the MA and GEO

- Fast-track IAV studies using the SRES (Arnell et al. 2004) reported a lack of sophisticated downscaling (including for narratives), although this issue was improved by later methods development (Grübler et al. 2007; van Vuuren et al. 2007) and the MA and GEO exercises.

- The SRES (in particular) lacked detailed references to many of the key factors responsible for shaping vulnerability and adaptive capacity, including multi-dimensional, subnational aspects of development and non-quantifiable aspects of institutional change or governance. As described above, individual studies made assumptions about such indicators and elements, although ad hoc procedures inevitably introduced inconsistencies between studies.

- The deterministic nature of many scenario efforts. Where climate models produce ensembles of projections, socioeconomic models project a single future per scenario, inherently reducing the representation of uncertainty (Arnell et al. 2004; Carter et al. 2001).

- Global scenarios are not necessarily developed to explore the full variation in factors relevant to IAV research, such as adaptive capacity in future worlds. For example, an extension of the income projections found in the SRES scenarios might plausibly have included variants that fixed or even decreased regional income, offering a wider range of potential impact outcomes (Arnell et al. 2004).

Table 1 describes variables and indicators from several global scenario sets, those added to the SRES scenarios in individual IAV studies for different sectors, and those included in two vulnerability indices (WRI and GAIN, see Section 2). There is considerable overlap in variables and indicators of vulnerability between the scenario sets and the indices. The dominant variables in the vulnerability indices are income/poverty, education, spatial population, population structure, health/life expectancy, infrastructure, and governance/resource management. 
Some of these variables are included traditionally in global scenario sets, such as GDP per capita, while others are extensions of traditional variables, such as education, dependency ratios, and life expectancy; the latter are included in the extended set of population projections for the SSPs (Lutz et al. 2013). Some elements, such as infrastructure, are available from IAM models (see e.g. Pachauri et al. 2013; Sassi et al. 2010). There are methods available to develop projections for other elements, such as poverty/income distribution, spatial population, health and governance, and a research agenda for pursuing this is presented in Section 4.2.

\section{Enhancing the SSPs and new scenarios for IAV studies}

The SSPs, and the new scenarios based on SSPs and RCPs provide an opportunity to reduce several of the limitations identified above for the use of scenarios in IAV work, including benefiting from lessons learnt in the MA and GEO exercises to improve applicability and coherence across scales. The SSPs and new scenarios can also include a richer set of elements more useful to projections of vulnerability and adaptive capacity. Below, we elaborate on efforts to improve working across scales and to developing a richer set of elements.

\subsection{Bottom-up and top-down approaches to developing scenarios across scales}

Spatio-temporal scale differences are an important challenge and hindrances to producing socioeconomic scenarios useful for IAV-research (Kriegler et al. 2012). More detailed spatial resolution is particularly relevant for local or regional IAV-studies, particularly those focusing on shorter time horizons (e.g. two decades). Several top-down or bottom-up methods exist to reconcile global scenarios can with local, regional, or sectoral IAV studies. Topdown methods would use the global SSPs as socioeconomic boundary conditions for downscaling. Such downscaling can be qualitative through developing narratives that represent regional or sector-specific storylines nested in, and therefore internally consistent with, the global pathways (e.g. Holman et al. 2005; Kok et al. 2011; Sleeter et al. 2012). Investment in developing qualitative storylines for regions or sectors offers flexibility for incorporating regional and/or sectoral knowledge and preferences to enhance the relevance of the storylines for such applications. For some applications, qualitative information may be sufficient to achieve study objectives (Rounsevell and Metzger 2010).

Narrative downscaling is often a procedural step when developing downscaled quantitative scenarios (van Vuuren et al. 2010). Having established the regional, local, and/or sectoral context to describe a set of alternative futures, those qualitative futures can be translated into quantitative indicators to facilitate subsequent analyses. Although there is no shortage of conceptual approaches, no standardized methods exist to facilitate that translation, making the process somewhat ad hoc and subject to the needs of individual studies and normative assumptions. By building on the experience with the SRES scenarios (Grübler et al. 2007; van Vuuren et al. 2007), various statistical and model-based downscaling methods can be applied, assuming some a priori, coarse-scale quantitative metrics to generate regionalized quantitative scenarios for relevant assessment indicators (van Vuuren et al. 2010). Although expedient, such approaches often develop scenarios for a limited suite of variables with little consideration of the broader socioeconomic context.

Although there are numerous examples of how global storylines and scenarios can be downscaled for regional/sectoral IAV applications, much IAV research and assessment proceeds bottom up. Therefore, there may be less demand among IAV researchers and practitioners for global scenarios as explicit boundary conditions, 
particularly when local trajectories and/or visions of the future appear disconnected from global-scale processes. While bottom-up approaches are likely to continue, mechanisms for constructing ex post links to the global scenarios would prove useful for collating diverse storylines and scenarios across scales to enable some degree of comparison (see e.g. Sietz et al. 2011). Those developing regional/sectoral storylines and scenarios should be encouraged to review those futures in the context of the global scenarios and, to the extent possible, map the former to the latter. Concepts such as sociotechnical imaginaries (Jasanoff and Kim 2009) can be helpful for linking local, regional and global scenarios. Such cross-scale mapping provides significant flexibility to the IAV community with respect to storyline/scenario development while still enabling a qualitative link to global scale socioeconomic processes.

Obviously, there are challenges that arise when working with scenarios across scales. Interactions between the local and the global level can transform local conditions in ways that matter very much for adaptation decisions at that scale, but where it has little impact at broader scales. In such circumstances, to force a global storyline on those local processes would be counterproductive. This issue is not limited to climate change and occurs in many situations of multi-level decision making. On the other hand, there are global factors often not considered in local and regional scale scenarios, such as trade and markets, that can have significant effects on projected impacts.

\subsection{A richer set of indicators to facilitate IAV analyses with SSPs}

Section 3 identified a number of indicators of interest to enhance the value of SSPs and new scenarios for IAV research. Adding projections of sub-national income distribution, spatial population, health, and governance would assist many IAV research projects in connecting to the global scenarios. In a way, this provides a prioritization of quantifying SSP elements as mentioned in O'Neill et al. (this issue) for IAV applications, although other researchers, policy-makers, and groups may suggest additional variables.

\subsubsection{Income distribution}

Adaptation studies take place at scales from national to household, with inequalities at each scale. Indicators that capture sub-national inequalities are important to guide location-based assessments of vulnerability and impact differentials. Past efforts to assess impacts locally have often had to rely on downscaling methods (Grübler et al. 2007; van Vuuren et al. 2007).

In response to growing demand by the IAV community for sub-national indicators, the SSPs aim to include quantitative projections of within-country income inequality and educational attainment. Literature on drivers of income inequalities stress the importance of structural and demographic change; physical and human capital accumulation; global trade and financial market integration and liberalization; technological progress; and policy and institutional factors (OECD 2011). In contrast to some scenarios of global income inequality (Calzadilla 2010; Hillebrand 2008) that assumed within-country income distributions do not change, the SSPs will construct trajectories of within-country income inequality. These quantitative projections of income inequality could be based on multiple methods and models, and could incorporate relevant drivers to varying degrees. Possible approaches include aggregate inequality measures at national scale based on social and institutional factors (Kemp-Benedict 2011), a parametric approach focusing on education differentials, a macroeconomic simulation (Hughes et al. 2009), and global macro-economic models combined with microsimulation (Busselo et al. 2010). Given the importance of multiple scales in IAV analysis, 
decomposable inequality indicators, such as the Theil index (Theil 1972), are preferable to non-decomposable or partially-decomposable indices like the Gini coefficient.

\subsubsection{Spatial population}

Spatial population projections are highly relevant for IAV analyses, where the location of people is one factor determining climate change risk (see e.g. Balk et al. 2012). Although there is lack of coherence between present-day datasets (Seto et al. 2011; Zhang and Seto 2011) and many different approaches exist (Angel et al. 2011), recent methods strengthened the connection between qualitative storylines and projected population outcomes. In contrast to earlier methods based on trend extrapolation and/or proportional scaling techniques, newer methods based on geographic gravity models can be calibrated to reflect spatial patterns of change in the historical data (Jones 2012). Furthermore, these models can be adjusted to reflect varying assumptions regarding the socioeconomic conditions that may impact future spatial patterns of development. Recent models project the urban/rural components of population and separately replicate urban and rural population dynamics. Additional improvements include improved spatial resolution, inclusion of geophysical spatial data (e.g., elevation, slope, surface water, and protected land) to better model habitable land, and exploration of the relationship between national socioeconomic indicators and subnational population distribution (e.g. Nam and Reilly 2013).

\subsubsection{Human health}

Projections of access to public health and health care services and burdens of diseases are relevant for vulnerability and adaptation assessments (McCarthy et al. 2010; van Lieshout et al. 2004). The SSPs could be enriched with projections based on methods such as the WHO global burden of disease (GBD) approach and the methods included in models, such as GISMO and International Futures (IFs). The GBD approach uses linear regression of mortality with GDP per capita, human capital, technological change and tobacco use for major disease clusters (Mathers and Loncar 2006). This approach makes no specific assumptions about the relationships between more distal socioeconomic factors and more proximate determinants of morbidity and mortality, such as environment, lifestyle, and physiological risk factors. The GISMO (Hilderink and Lucas 2008) and IFs (Hughes et al. 2011) models complement the GBD approach to address some of these issues. Both models include approaches to simulate the health system and to address morbidity and mortality as a result of exposure to distal and proximate socioeconomic and environmental health risks.

\subsubsection{Governance}

Elaborating on governance is crucial to application of the SSPs and new scenarios for IAV research. The current SSP narratives include only a basic description of governance at the international and national level (O'Neill et al. forthcoming). It is difficult to include governance dimensions in global integrated assessment models, although several attempts exist (e.g. Hughes et al. 2013). For global scenario-analysis, it seems more fruitful to have different governance parameters influencing model input parameters rather than including these in the models (de Vos et al. 2013). A key-issue for elaborating governance is not only to find quantitative indicators for governance itself, but also to elaborate on how different scientific perspectives on governance and potential future development in governance scenarios play out 
in terms of quantitative indicators for development, vulnerability, and adaptive capacity. Based on the Earth System Governance project (Biermann et al. 2009) and the SSPs could provide more elaborate descriptions of governance that reflect recent trends in governance thinking, from government focused to distinguishing multi-actor, multi-level governance.

\section{Discussion and conclusion}

The SSPs and new scenarios will be crucial for improved projections and assessments of climate change risks and options for their management. They can improve coherence in the growing body of regional scenario studies, provide global boundary conditions to frame regional studies and inform large-scale impact, adaptation and vulnerability assessments. Strategies to reduce vulnerability and increase adaptive capacities of societies facing climate change risks have to account for a variety of potential changes in societal conditions. The usefulness of the SSPs and new scenarios would be enhanced for IAV researchers by adding a richer set of elements to the projections - including income distribution, spatial population, human health, and governance - and by improving scenario application across spatial and temporal scales. This paper suggests a research agenda to start this process.

As part of the broader 'parallel' scenario process (Moss et al. 2010), the scenarios provide a range of new opportunities for integrating alternative socioeconomic and climatic futures for the purposes of local, regional, or sectoral impact analyses and for evaluating possible adaptation and mitigation policies (van Vuuren et al. 2012b). In contrast to the SRES storylines and scenarios, the matrix architecture of the new scenarios allows greater flexibility in exploring combinations of socioeconomic and climate futures from multiple alternatives. For regional/sectoral applications, climate projections based on the RCPs may need to be downscaled to generate climate information at the scales relevant for particular IAV applications. The IAV community is sensitive to uncertainty in model projections for a given RCP and thus often uses multi-model ensembles to explore the uncertainty space associated with different model realizations of the future climate. A similar approach might be desired in using multiple socioeconomic models (or IAMs) for each SSP.

One of the remaining challenges is how to balance the need for producing long-term averaged/smoothed scenarios of socioeconomic development with the interest to remain sensitive to crises and shocks at local/regional and decadal scales. The latter are of great importance for the vulnerability and impact context as they might trigger longterm-positive or negative - changes in terms of vulnerability and adaptive capacity (Birkmann et al. 2010). One possible way forward would be to integrate the possibility for medium scale fluctuations - e.g. economic crises or a major pandemic - into the scenarios and to assess whether and how such events might alter the speed and direction of the larger pathway. Such amendments can provide important and policy-relevant bridges and insights.

Open Access This article is distributed under the terms of the Creative Commons Attribution License which permits any use, distribution, and reproduction in any medium, provided the original author(s) and the source are credited.

\section{References}

Angel S, Parent J, Civco DL, Blei A et al (2011) The dimensions of global urban expansion: estimates and projections for all countries, 2000-2050. Prog Plan 75:53-107. doi:10.1016/j.progress.2011.04.001 
Arnell NW, Livermore MJL, Kovats S, Levy PE et al (2004) Climate and socio-economic scenarios for globalscale climate change impacts assessments: characterising the SRES storylines. Glob Environ Chang 14:3-20. doi:10.1016/j.gloenvcha.2003.10.004

Balk D, Montgomery MR, Liu Z (2012) Urbanization and climate change hazards in Asia. Population Association of America, 2013 Annual Meeting, New Orleans, LA

Barnett J, Lambert S, Fry I (2008) The hazards of indicators: insights from the environmental vulnerability index. Ann Assoc Am Geogr 98:102-119. doi:10.1080/00045600701734315

Berkhout F, Hertin J, Jordan A (2002) Socio-economic futures in climate change impact assessment: using scenarios as 'learning machines'. Glob Environ Chang 12:83-95. doi:10.1016/S0959-3780(02)00006-7

Biermann F, Betsill MM, Gupta J, Kanie N et al (2009) Earth system governance science plan. The Earth System Governance Project, Bonn

Birkmann J, Buckle P, Jaeger J, Pelling M et al (2010) Extreme events and disasters: a window of opportunity for change? Analysis of organizational, institutional and political changes, formal and informal responses after mega-disasters. Nat Hazards 55:637-655. doi:10.1007/s11069-008-9319-2

Birkmann J, Krause D, Setiadi NJ, Suarez D et al (2011) WorldRiskReport 2011. Alliance Development Works, Berlin

Birkmann J, Cutter S, Rothman DS, Welle T et al (2013) Scenarios for vulnerability: opportunities and constraints in the context of climate change and disaster risk. Clim Chang accepted

Busselo M, De Hoyos RE, Medvedev D (2010) Economic growth and income distribution: linking macroeconomic models with household survey data at the global level. Int J Microsimulation 3:91-103

Calzadilla A (2010) Global income distribution and poverty: implications from the IPCC SRES scenarios. Kiel Institute for the World Economy, Kiel

Carpenter SR, Pingali PL, Bennett EM, Zurek MB (eds) (2005) Ecosystems and human well-being: scenarios. Findings of the Scenarios Working Group of the Millennium Ecosystem Assessment. Island Press, Washington, DC

Carter TR, La Rovere EL, Jones R, Leemans R et al (2001) Developing and applying scenarios. In: McCarthy JJ, Canziani OF, Leary NA, Dokken DJ, White KS (eds) Climate change 2001: Working Group II: impacts, adaptation and vulnerability. Cambridge University Press, Cambridge, pp 145-190

Carter TR, Fronzek S, Bärlund I (2004) FINSKEN: a framework for developing consistent global change scenarios for Finland in the 21st century. Boreal Environ Res 9:91-107

Carter TR, Jones R, Lu X, Bhadwal S et al (2007) New assessment methods and the characterisation of future conditions. In: Parry ML, Canziani OF, Palutikof JP, van der Linden PJ, Hanson CE (eds) Climate change 2007: impacts, adaptation and vulnerability. Contribution of Working Group II to the fourth assessment report of the Intergovernmental Panel on Climate Change. Cambridge University Press, Cambridge, pp 133-171

de Vos MG, Janssen PHM, Kok MTJ, Frantzi S et al (2013) Formalizing knowledge on international environmental regimes: a first step towards integrating political science in integrated assessments of global environmental change. Environ Model Softw 44:101-112. doi:10.1016/j.envsoft.2012.08.004

Döll P (2009) Vulnerability to the impact of climate change on renewable groundwater resources: a globalscale assessment. Environ Res Lett 4:035006

Ebi KL, Hallegatte S, Kram T, Arnell NW et al (this issue) A new scenario framework for climate change research: background, process, and future directions. Clim Chang

Funfgeld H, McEvoy D (2011) Framing climate change adaptation in policy and practice. Victorian Centre for Climate Change Adaptation Research, Melbourne

Gaffin SR, Rosenzweig C, Xing X, Yetman G (2004) Downscaling and geo-spatial gridding of socioeconomic projections from the IPCC Special Report on Emissions Scenarios (SRES). Glob Environ Chang 14:105-123.. doi:10.1016/j.gloenvcha.2004.02.004

Global Adaptation Institute (2011) GlobalAdaptation Index (GAIN) - measuring what matters. Global Adaptation Institute, Washington, DC

Golding N, Betts R (2008) Fire risk in Amazonia due to climate change in the HadCM3 climate model: potential interactions with deforestation. Global Biogeochem Cycles 22, GB4007. doi:10.1029/ $2007 \mathrm{gb} 003166$

Grübler A, O’Neill B, Riahi K, Chirkov V et al (2007) Regional, national, and spatially explicit scenarios of demographic and economic change based on SRES. Technol Forecast Soc Chang 74:980-1029. doi:10.1016/j.techfore.2006.05.023

Hallegatte S, Przyluski V, Vogt-Schilb A (2011) Building world narratives for climate change impact, adaptation and vulnerability analyses. Nat Clim Chang 1:151-155

Harrison PA, Holman IP, Cojocaru G, Kok K et al (2012) Combining qualitative and quantitative understanding for exploring cross-sectoral climate change impacts, adaptation and vulnerability in Europe. Reg Environ Chang 1-20. doi:10.1007/s10113-012-0361-y

Hilderink HBM, Lucas PL (eds) (2008) Towards a global integrated sustainability model: GISMO 1.0 status report. Netherlands Environmental Assessment Agency (PBL), Bilthoven 
Hillebrand E (2008) The global distribution of income in 2050. World Dev 36:727-740. doi:10.1016/ j.worlddev.2007.05.013

Hinkel J (2011) "Indicators of vulnerability and adaptive capacity": towards a clarification of the sciencepolicy interface. Glob Environ Chang 21:198-208. doi:10.1016/j.gloenvcha.2010.08.002

Hinkel J, van Vuuren DP, Nicholls RJ, Klein RJT (2012) The effects of adaptation and mitigation on coastal flood impacts during the 21st century. An application of the DIVA and IMAGE models. Clim Chang 112. doi:10.1007/s10584-012-0564-8

Holman IP, Rounsevell MDA, Shackley S, Harrison PA et al (2005) A regional, multi-sectoral and integrated assessment of the impacts of climate and socio-economic change in the UK. Clim Chang 71:9-41. doi:10.1007/s10584-005-5927-y

Hughes B, Irfan M, Khan H, Kumar K et al (2009) Reducing global poverty. Vol. 1 of the patterns of potential human progress series. Paradigm Publishers and Oxford University Press, Boulder, and New Delhi

Hughes BB, Kuhn R, Peterson C, Rothman DS et al (2011) Improving global health. Vol. 3 of the patterns of potential human progress series. Paradigm Publishers and Oxford University Press, Boulder and New Delhi

Hughes BB, Joshi DK, Moyer JD, Sisk TD et al (2013) Strengthening governance globally: the next 50 years. Paradigm Publishers, Boulder

IPCC (2012) Managing the risks of extreme events and disasters to advance climate change adaptation. A special report of Working Groups I and II of the Intergovernmental Panel on Climate Change. Cambridge University Press, Cambridge

Jasanoff S, Kim S-H (2009) Containing the atom: sociotechnical imaginaries and nuclear power in the United States and South Korea. Minerva 47:119-146. doi:10.1007/s11024-009-9124-4

Jones B (2012) Assessment of the potential-allocation downscaling methodology for constructing spatial population projections. NCAR technical note. National Center for Atmospheric Research, Boulder

Kemp-Benedict E (2011) Political regimes and income inequality. Econ Lett 113:266-268. doi:10.1016/ j.econlet.2011.08.002

Kok K, van Vliet M, Bärlund I, Dubel A et al (2011) Combining participative backcasting and exploratory scenario development: experiences from the SCENES project. Technol Forecast Soc Chang 78:835-851. doi:10.1016/j.techfore.2011.01.004

Kriegler E, O’Neill BC, Hallegatte S, Kram T et al (2012) The need for and use of socio-economic scenarios for climate change analysis: a new approach based on shared socio-economic pathways. Glob Environ Chang 22:807-822. doi:10.1016/j.gloenvcha.2012.05.005

Kriegler E, Edmonds J, Hallegatte S, Ebi KL et al (this issue) A new scenario framework for climate change research: the concept of shared climate policy assumptions. Clim Chang

Lutz W, Butz B, Samir KC (2013) World population and human capital in the 21 st century. Oxford University Press, Oxford

Mathers CD, Loncar D (2006) Projections of global mortality and burden of disease from 2002 to 2030. PLoS Med 3:2011-2030

McCarthy MP, Best MJ, Betts RA (2010) Climate change in cities due to global warming and urban effects. Geophys Res Lett 37, L09705. doi:10.1029/2010g1042845

Metzger MJ, Schröter D, Leemans R, Cramer W (2008) A spatially explicit and quantitative vulnerability assessment of ecosystem service change in Europe. Reg Environ Chang 8:91-107. doi:10.1007/s10113008-0044-X

Moss RH, Edmonds JA, Hibbard KA, Manning MR et al (2010) The next generation of scenarios for climate change research and assessment. Nature 463:747-756. http://www.nature.com/nature/journal/v463/ n7282/suppinfo/nature08823 S1.html

Nakicenovic N, Alcamo J, Davis G, de Vries B et al (2000) Special report on emissions scenarios: a special report of Working Group III of the Intergovernmental Panel on Climate Change. Intergovernmental Panel on Climate Change. Cambridge University Press, Cambridge

Nam K-M, Reilly JM (2013) City size distribution as a function of socioeconomic conditions: an eclectic approach to downscaling global population. Urban Stud 50:208-225. doi:10.1177/0042098012448943

Nicholls RJ (2004) Coastal flooding and wetland loss in the 21st century: changes under the SRES climate and socio-economic scenarios. Glob Environ Chang 14:69-86. doi:10.1016/j.gloenvcha.2003.10.007

OECD (2011) Divided we stand - why inequality keeps rising. OECD, Paris

O’Neill BC, Kriegler E, Kemp-Benedict E, Ebi KL et al (forthcoming) The Shared Socioeconomic Pathways: narratives

O’Neill BC, Kriegler E, Riahi K, Ebi KL et al (this issue) A new scenario framework for climate change research: the concept of shared socio-economic pathways. Clim Chang

Pachauri S, van Ruijven BJ, Nagai Y, Riahi K et al (2013) Pathways to achieve universal household access to modern energy by 2030. Environ Res Lett 
Parry ML, Rosenzweig C, Iglesias A, Livermore M et al (2004) Effects of climate change on global food production under SRES emissions and socio-economic scenarios. Glob Environ Chang 14:53-67. doi:10.1016/j.gloenvcha.2003.10.008

Pérez Urrestarazu L, Smout I, Rodríguez Díaz J, Carrillo Cobo M (2010) Irrigation distribution networks' vulnerability to climate change. J Irrig Drain Eng 136:486-493. doi:10.1061/(ASCE)IR.1943-4774.0000210

Preston B, Stafford-Smith M (2009) Framing vulnerability and adaptive capacity assessment: discussion paper. CSIRO, Aspendale

Preston BL, Yuen EJ, Westaway RM (2011) Putting vulnerability to climate change on the map: a review of approaches, benefits, and risks. Sustain Sci 6:177-202. doi:10.1007/s11625-011-0129-1

Ribot JC (1995) The causal structure of vulnerability: its application to climate impact analysis. GeoJournal 35:119-122. doi:10.1007/BF00814058

Rothman DS, Romero Lankao P, Schweizer V, Bee B (this issue) Challenges to adaptation: a fundamental concept for a new generation of socioeconomic scenarios. Clim Chang

Rounsevell MDA, Metzger MJ (2010) Developing qualitative scenario storylines for environmental change assessment. WIREs Clim Chang 1:606-619

Rounsevell MDA, Reginster I, Araújo MB, Carter TR et al (2006) A coherent set of future land use change scenarios for Europe. Agric Ecosyst Environ 114:57-68. doi:10.1016/j.agee.2005.11.027

Sassi O, Crassous R, Hourcade J-C, Gitz V et al (2010) IMACLIM-R: a modelling framework to simulate sustainable development pathways. Int J Glob Environ Issues 10:5-24. doi:10.1504/IJGENVI.2010.030566

Seto KC, Fragkias M, Güneralp B, Reilly MK (2011) A meta-analysis of global urban land expansion. PLoS ONE 6:e23777. doi:10.1371/journal.pone.0023777

Sietz D, Lüdeke MKB, Walther C (2011) Categorisation of typical vulnerability patterns in global drylands. Glob Environ Chang 21:431-440. doi:10.1016/j.gloenvcha.2010.11.005

Sleeter BM, Sohl TL, Bouchard MA, Reker RR et al (2012) Scenarios of land use and land cover change in the conterminous United States: utilizing the special report on emission scenarios at ecoregional scales. Glob Environ Chang 22:896-914. doi:10.1016/j.gloenvcha.2012.03.008

Smith B, Burton I, Klein RT, Wandel J (2000) An anatomy of adaptation to climate change and variability. Clim Chang 45:223-251. doi:10.1023/A:1005661622966

Taylor KE, Stouffer RJ, Meehl GA (2011) An overview of CMIP5 and the experiment design. Bull Am Meteorol Soc 93:485-498. doi:10.1175/bams-d-11-00094.1

Theil H (1972) Statistical decomposition analysis: with applications in the social and administrative sciences. North-Holland Pub, Co

UNEP (2002) Global environment outlook 3. United Nations Environment Programme, London

UNEP (2007) Global environment outlook 4: environment for development. United Nations Environment Program, Nairobi

van Lieshout M, Kovats RS, Livermore MTJ, Martens P (2004) Climate change and malaria: analysis of the SRES climate and socio-economic scenarios. Glob Environ Chang 14:87-99. doi:10.1016/j.gloenvcha.2003.10.009

van Vuuren DP, Lucas PL, Hilderink H (2007) Downscaling drivers of global environmental change: enabling use of global SRES scenarios at the national and grid levels. Glob Environ Chang 17:114-130

van Vuuren DP, Smith SJ, Riahi K (2010) Downscaling socioeconomic and emissions scenarios for global environmental change research: a review. Wiley Interdiscip Rev Clim Chang 1:393-404. doi:10.1002/wcc.50

van Vuuren DP, Edmonds J, Kainuma M, Riahi K et al (2011) The representative concentration pathways: an overview. Clim Chang 109:5-31. doi:10.1007/s10584-011-0148-z

van Vuuren DP, Kok MTJ, Girod B, Lucas PL et al (2012a) Scenarios in global environmental assessments: key characteristics and lessons for future use. Glob Environ Chang 22:884-895. doi:10.1016/ j.gloenvcha.2012.06.001

van Vuuren DP, Riahi K, Moss R, Edmonds J et al (2012b) A proposal for a new scenario framework to support research and assessment in different climate research communities. Glob Environ Chang 22:2135. doi:10.1016/j.gloenvcha.2011.08.002

van Vuuren DP, Kriegler E, O’Neill BC, Ebi KL et al (this issue) A new scenario framework for climate change research: scenario matrix architecture. Clim Chang

Verburg P, Eickhout B, Meijl H (2008) A multi-scale, multi-model approach for analyzing the future dynamics of European land use. Ann Reg Sci 42:57-77. doi:10.1007/s00168-007-0136-4

Wilbanks T, Ebi KL (this issue) SSPs from an impact and adaptation perspective. Clim Chang

Wu W, Tang H, Yang P, You L et al (2011) Scenario-based assessment of future food security. J Geogr Sci 21:3-17. doi:10.1007/s11442-011-0825-x

Zhang Q, Seto KC (2011) Mapping urbanization dynamics at regional and global scales using multi-temporal DMSP/OLS nighttime light data. Remote Sens Environ 115:2320-2329. doi:10.1016/j.rse.2011.04.032

Zurek MB, Henrichs T (2007) Linking scenarios across geographical scales in international environmental assessments. Technol Forecast Soc Chang 74:1282-1295. doi:10.1016/j.techfore.2006.11.005 